\title{
Contabilidade: A Cibernética Empresarial
}

\author{
Victor Branco de Holanda \\ Doutorando em Controladoria e Contabilidade pela FEA/USP \\ Contador, economista e professor da Universidade Federal \\ do Rio Grande do Norte
}

RESUMO

A empresa pode ser vista como um sistema aberto capaz de trocar energia com seu ambiente ou, mais modernamente, como um sistema eminentemente social. A compreensão de um sistema não pode ser obtida apenas através da análise; estudá-lo cientificamente é descobrir, sobretudo, o interrelacionamento entre as partes. Profissões e empregos de análise de sistemas, engenharia de sistemas surgiram como decorrência do enfoque sistêmico. A teoria moderna das organizações passa pela discussão da Teoria Geral dos Sistemas, que acaba sendo uma maneira inteligível de estudar uma organização. Outra repercussão decorrente do enfoque sistêmico é a interdisciplinaridade. (abordagem adequada ao estudo e compreensão da função contábil, pois esta é resultado direto dos modelos de decisão utilizados por seus usuários). A informação contábil pode contribuir para a percepção e compreensão das entidades empresariais modernas como entes sistêmicos, objeto de interesse de vários grupos sociais.

Palavras-chave: Teleológico, Casualidade, Interdisciplinaridade, Cibernética, Sistemas sociais e Redes neurais.
ABSTRACT

The company can be seen as an open system capable of exchanging energy with its environment, but, in a modern view, as an eminently social system. The understanding of a system cannot be obtained through analysis. To study it scientifically means to discover, above all, the interrelationship between the parts. System analysis professions and jobs, system engineering arose as a result of the systemic focus. Modern organizational theory goes through the discussion of General Systemic Theory, which ends up being an intelligible way of studying an organization. Another repercussion that results from the systemic focus is interdisciplinariness. This is an adequate approach to the study and understanding of the accounting function, because it is a direct result of the decision models used by its users. Accounting information can contribute to the perception and comprehension of modern company entities as systemic beings, which is an object that interests different social groups.

Key words: Teleological, Causality, Interdisciplinariness, Cybernetics, Social systems, Neural networks. 


\section{INTRODUÇÃO}

A Contabilidade, enquanto ciência do controle patrimonial, está diretamente associada ao grau de desenvolvimento das sociedades, cidades ou nações. Neste estudo, discutem-se as repercussões do ambiente atual, fortemente influenciado pelas novas tecnologias de informação, na Contabilidade, em seus aspectos mais relevantes. Para isso, investigam-se as raízes do enfoque sistêmico, com base principalmente na Teoria Geral dos Sistemas de Bertalanffy (1968) e seus desdobramentos como a obra de Churchman (1972). A partir dessas raízes, procura-se uma identificação com o chamado mundo da cibernética, área do conhecimento relativamente nova e promissora. Tenta-se vincular a cibernética com o arcabouço teórico da Contabilidade e seu objetivo. Ainda nesse contexto, procura-se caracterizar uma metodologia adequada para a abordagem das entidades atuais e para a identificação de complexidades. Em decorrência disto, surge um outro elo - as redes neurais - como forma de identificação e mensuração de algumas realidades complexas.

Um fato que merece registro, desde já, é que se pretende fazer um recorte transversal nesses assuntos, em vez de uma aproximação verticalizada e profunda. Assim, a preocupação é com o interrelacionamento dos temas. Não obstante, tenta-se, ao final do estudo, apresentar de forma objetiva algumas conclusões pontuais.

\section{1) O ENFOQUE SISTÊMICO}

Na percepção mecanicista do mundo, nascida da física clássica, os fenômenos eram regidos pelas leis da causalidade, produzindo todos os fenômenos inanimados, vivos e mentais. Não havia lugar para a direção, a ordem ou a finalidade. Os organismos eram concebidos como um produto do acaso, conseqüência de mutações ocasionais e processo de seleção. $\mathrm{Na}$ "Física Social1 ", segundo Buckley (1971, p.24), o homem era considerado um objeto físico, espécie de máquina complicada. Em conseqüência, suas ações e processos psíquicos poderiam ser analisados em função dos princípios da mecânica. A sociedade era percebida como um sistema astronômico, cujos elementos eram seres humanos ligados pela atração mútua ou diferenciados pela repulsão. Grupos de sociedades ou Estados constituíam sistemas de oposições equilibradas. $\mathrm{O}$ homem, seus grupos $\mathrm{e}$ suas inter-relações constituíam uma espécie de continuidade com o resto do universo, mecanisticamente interpretado.

Uma parte da chamada ciência contemporânea questionou o paradigma mecanicista-reducionista resgatando a noção de totalidade e unidade de antigos pensadores. Um velho questionamento retorna ao novo ambiente científico: existem leis gerais que se aplicam a qualquer sistema de certo tipo, independentemente das propriedades particulares do sistema e dos elementos em questão? Esse estado de coisas enseja a possibilidade da existência de uma teoria geral?

Dentre as denominadas teorias globais a enunciada por Bertalanffy em 1947 sob o título de "Teoria geral dos sistemas" conseguiu manter-se. As raízes desta evolução são complexas. Segundo Bertalanffy (1972, p.18), um fato relevante foi à passagem da engenharia de produção de energia (representada pelo motor a vapor e elétrico) para a engenharia de controle (representada pelos semicondutores - silício) que dirige processos empregando dispositivos de baixa potência. Tal passagem proporcionou o surgimento dos computadores e da automação. Hoje um certo número de modernas abordagens tem suas raízes na Teoria Geral dos Sistemas, tais como a teoria da informação, a cibernética, a teoria dos jogos, das redes, os modelos estocásticos, a pesquisa operacional, entre outras.

O fato é que de uma maneira ou de outra tratar com complexos, com "totalidades" (ou sistemas) em todos os campos de conhecimento é uma necessidade. O problema do sistema é essencialmente o problema das limitações dos procedimentos analíticos na ciência.

Estudar um sistema de forma científica é descobrir o inter-relacionamento entre as partes. Declara-se então que para ser um sistema, um conjunto de itens

\footnotetext{
${ }^{1}$ Um estudo da escola mecanicista da sociologia pode ser encontrado, por exemplo, em SOROKIN, Pitirim A. Contemporary Sociological Theories Nessa abordagem, tentase explicar o homem e a sociedade com os mesmos métodos, conceitos e suposições da Física, da Mecânica e da Matemática do século XVII.
} 
não tem somente os $n$ elementos para serem estudados, mas $n(n-1)$ relações. Por exemplo, num conjunto de sete elementos existem 42 relações. Porém pode-se avançar e definir um estado desse sistema como o comportamento produzido na rede. Assim haverá $2^{42}$ diferentes estados para o sistema, o que representa um número excessivamente grande. Esta é a razão porque um rigoroso enfoque sistêmico é difícil e pouco usual.

Apesar da dificuldade aludida, segundo Bertalanffy (1972, p.17), profissões e empregos desconhecidos até pouco tempo atrás, tendo os nomes de projeto de sistemas, análise de sistemas, engenharia de sistemas surgiram como decorrência do enfoque sistêmico. Numa primeira tentativa de diferenciação do que seria um enfoque sistêmico em contraposição ao analítico, de forma simplificada, poderia ser: ao se defrontar com um problema complexo, o enfoque analítico tentaria dividi-lo para melhor compreendê-lo e, então, propor uma solução. Já no enfoque sistêmico, a primeira providencia é compreender o problema como um todo relacionando as partes e, em seguida, iniciar a busca da solução.

Alguns conceitos desconsiderados na física convencional passaram a ser abordados na teoria dos sistemas, tais como causalidade, teleologia, equifinalidade etc. $O$ conceito de organização foi ampliado, procurando-se enquadrar, num mesmo contexto, por exemplo, um átomo, um cristal, uma molécula ou uma empresa. Estes organismos possuem, assim, características comuns, como crescimento, diferenciação, ordem hierárquica, controle, competição etc. Características essas presentes seja em um organismo vivo, seja numa empresa, numa sociedade ou numa nação.

A empresa, a partir de então, passou a ser considerada como um sistema aberto, capaz de trocar energia com seu ambiente. Desta forma, a teoria moderna das organizações inclui, quase inevitavelmente, uma discussão da teoria geral dos sistemas, a qual, por sua vez, se molda por uma filosofia que adota a premissa de que a única maneira inteligível de se estudar uma organização é estudá-la como sistema.

\section{2) O QUE É CIBERNÉTICA}

A palavra vem do grego e, entre eles, no princípio, servia para designar o saber que permite ao piloto conduzir adequadamente a sua embarcação.

Para Bennaton (1984, p.10), a cibernética questiona os limites que separam animais, homens e máquinas. Tem por missão procurar um enquadramento maior, no qual as coisas naturais e aquelas fabricadas pelos homens se insiram como itens de uma harmoniosa paisagem. Para essa nova geração de pensadores não há, como parece, uma grande diversidade no mundo dos sistemas quando o elemento de comparação é o seu comportamento. Há mais semelhanças do que diferenças ${ }^{2}$. A tarefa da cibernética então é tornar explícitas as leis que governam o comportamento dos sistemas, sejam eles de natureza elétrica, orgânica, geológica, econômica, social etc.

Após a Segunda Guerra Mundial, as pessoas depararam-se com problemas referentes a controle eletrônico, em diversos tipos de máquinas. Os matemáticos discutiam o comportamento da informação dentro dos circuitos elétricos, tentando sua modelagem através de algoritmos. Outros se preocupavam em entender como a informação poderia ser codificada. Os biólogos, por sua vez, interessavam-se em descobrir como a informação exercia controle no corpo dos animais. $O$ fato é que médicos, engenheiros, psiquiatras, entre outros profissionais, também se interessavam pelo assunto. Segundo Beer (1969, p.18), esses profissionais, gradativamente, começaram a perceber que estavam pesquisando sobre a o mesmo assunto - o princípio básico do controle -, apesar da barreira construída pelas suas diferentes linguagens profissionais. $\mathrm{Beer}^{3}$ relata ainda que esse grupo de cientistas reuniu-se originalmente em torno da figura do matemático Norbert Wiener. Assim, por volta de 1947, decidiram que seu trabalho tinha proporcionado um novo campo científico e batizaram essa ciência de cibernética, cuja tarefa seria a busca de uma unidade fundamental entre os mecanismos de controle em várias ciências diferentes. Norbert Wiener usa o termo, então, para designar o domínio todo da teoria da comunicação e

\footnotetext{
2 Dois sistemas são considerados equivalentes quando um reproduz o comportamento do outro. Uma colônia de coelhos e um investimento podem ser expressos pelo mesmo algoritmo matemático, ou seja, quantidade (ou montante) $=\mathrm{q}$ inicial (ou capital) $\mathrm{x}(1+\mathrm{i})^{\mathrm{n}}$

3 Todos os autores pesquisados conferem a Norbert Wiener papel preponderante no surgimento da Cibernética.
} 
do controle, tanto na máquina quanto no animal. $\mathrm{E}$ estendendo-se, segundo Heylighen (1993: p 1), para a sociedade e os seres humanos individualmente.

Ainda segundo Heylighen, a cibernética cresceu a partir da teoria da informação de Shannon, que foi projetada para aperfeiçoar a transmissão de informação através de canais de comunicação e o conseqüente estudo do conceito de realimentação no uso dos sistemas de controle. Em sua versão atual, sua ênfase está em como os observadores constróem modelos dos sistemas com os quais interagem.

A ênfase principal da cibernética atribui-se aos mecanismos circulares que permitem aos sistemas complexos se manterem, adaptarem, e autoorganizarem. Tal circularidade, ou auto-referência, torna possível a construção de modelos com comportamento orientado para uma meta ou condição. Assim, a cibernética se propõe a uma revolução no que diz respeito ao linear, ao modelo mecanicista da ciência newtoniana tradicional. Em ciência clássica, todo processo é somente determinado por sua causa, ou seja, um fator que reside no passado. Entretanto, o comportamento de organismos viventes ${ }^{4}$ é tipicamente teleológico, orientado para um estado futuro que ainda não existe.

A cibernética defende que aspecto teleológico (ou finalidade) e causalidade podem ser reconciliados empregando-se mecanismos não-lineares, circulares, nos quais a causa se iguala ao efeito, como, por exemplo, na realimentação. A aplicação mais simples de realimentação para automanutenção é a homeostase. A interação não-linear entre a meta do sistema e seu ambiente resulta em uma relação de controle, por parte do sistema, em relação às perturbações que vêm do ambiente.

Um fato interessante, que auxilia a visualização do surgimento da nova ciência, foi relatado por Beer (1969, p. 18), quando dois pesquisadores do grupo estavam projetando uma máquina capaz de permitir aos cegos ler. Não era nova a idéia de que uma célula fotoelétrica poderia ser usada para examinar uma linha impressa e produzir tons audíveis, os quais poderiam, de alguma maneira, representar as letras e palavras escritas. O aparelho proposto envolvia uma leitura seletiva por um processo automático minucioso. Foi preparado um diagrama esquemático da máquina que, segundo Wiener apud Beer (1969, p. 19), chamou a atenção de um eminente anatomista que pertencia ao grupo de estudo. Ele perguntou: "será isso o diagrama da quarta camada do córtex visual do cérebro?" Este é o primeiro exemplo da maneira pela qual a teoria do controle começou a progredir por meio da união das ciências estabelecidas. Passos importantes para o que se chama hoje de interdisciplinaridade estavam sendo dados. Alguns biólogos rapidamente perceberam o valor da cibernética para a sua área de estudo. Engenheiros vislumbraram aplicações em particular para a automação. Antropólogos levantam a hipótese de uma estrutura cibernética para as ciências sociais. Os economistas adotam um ponto de vista similar. Hoje não é difícil encontrar a cibernética no auxílio de problemas administrativos com maior ênfase na administração industrial. No entanto, na opinião de Beer, isso não esclarece qual é o alcance real e o significado da nova ciência. E a questão que, neste momento, se propõe de forma introdutória é: a Contabilidade estaria imune a essa revolução?

\section{3) UMA CONTABILIDADE ADEQUADA A UMA NOVA EMPRESA}

Antes de passar propriamente para a identificação dessa nova empresa, faz-se necessária uma introdução a respeito das visões alternativas de um sistema. Para isso, observa-se a classificação proposta por Ackoff (1999, p.2), quando considera três tipos de sistemas: mecânico, orgânico e social.

Os sistemas mecânicos operam com extrema regularidade, oriunda da sua estrutura interna e pelas leis causais da natureza. Esses sistemas não têm, por si só, nenhuma escolha, por conseqüência não têm finalidades, embora possuam funções, quais sejam: alcançar as metas determinadas por uma entidade externa. Assim, na mesma linha de raciocínio, as partes de um sistema mecânico possuem subfunções. Um exemplo apresentado por Ackoff elucida a questão: um automóvel é um sistema mecânico que, por si só, não tem finalidade, mas atende às necessidades de seu motorista, funcionando como meio de locomoção. Nesse sentido, a bomba de combustível tem a função de enviar combustível ao motor.

${ }^{4}$ A palavra vivente pode ter um amplo alcance, incluindo uma organização do tipo empresa ou o ciclo de vida de um produto. 
Os sistemas orgânicos são os que têm pelo menos um objetivo ou meta própria. Por exemplo, a sobrevivência, para a qual o crescimento normalmente é considerado essencial. Suas partes não têm metas ou objetivos, entretanto têm funções para atender à meta ou objetivo do sistema todo. Os sistemas orgânicos são abertos, portanto, sujeitos à influência do meio. As partes de um sistema orgânico tanto podem ser essenciais como, por exemplo, o pulmão, quanto não-essenciais como, por exemplo, os cabelos.

Sistemas sociais são sistemas abertos, que têm finalidade própria; contêm no mínimo uma parte essencial (com finalidade própria) e fazem parte de sistemas maiores, por sua vez, com finalidades próprias.

É interessante a reflexão de Ackoff (1999, p.3), de que sistemas mecânicos, orgânicos e sociais são conceitos (ou entidades). Pode-se, portanto, compreender uma entidade sob o prisma de qualquer um dos tipos de sistemas: uma empresa, uma escola, ou um país, pode ser, em princípio, conceituado e percebido como máquina, organismo ou sistema social, e, conseqüentemente, gerido e controlado conforme essa concepção.

A entidade empresa como máquina - Quando da revolução industrial, segundo Ackoff (1999, p.3), a visão newtoniana do mundo prevalecia, além da crença de que o universo era a "máquina", criada por Deus para executar a sua vontade. Conseqüentemente, as pessoas (criadas à imagem do seu criador) deveriam imitar a Deus: criar máquinas para executar seu trabalho. Assim, o autor conclui: "Não é de admirar que as empresas fossem consideradas máquinas criadas por seus deuses (ou donos) para executar o trabalho deles. Esses sistemas não tinham uma finalidade própria, mas supunha-se que tinham a função de atender aos objetivos de seus donos: proporcionar um retorno de seu investimento, através da geração de lucros".

Por conseqüência dessa visão, os donos eram onipotentes, praticamente desobrigados de leis, tinham a empresa como sua propriedade e podiam fazer o que quisessem com ela. Por extensão, os funcionários eram peças dessa máquina, sem finalidade própria, a não ser cumprir a função de atender à finalidade imposta por seu dono. Além disso, os funcionários eram considerados "não essenciais", pois podiam ser facilmente substituídos, já que o trabalho requeria pouca habilidade e havia grande quantidade de peças (trabalhadores) disponíveis, dispostas a funcionar (trabalhar) sob quaisquer condições para escapar da miséria.

Outra consequência da empresa compreendida como máquina é que sua organização e administração existem para restringir o comportamento de suas partes. A eficácia da máquina depende de sua capacidade de manter suas partes fazendo a mesma coisa repetidamente.

\section{A Contabilidade para uma empresa conceituada como máquina}

Os sistemas interagem muito mais do que tradicionalmente se pensa. A Contabilidade, quando aceita como ciência social, está sujeita às influências [do ambiente] e reflete, quer se tenha consciência quer não, um grande conjunto de forças, ditas sociais. Neste sentido, a Contabilidade se amoldou para atender aos anseios daqueles que queriam perceber a empresa, ou entidade, sob o prisma do sistema mecânico. Assim, a teoria do proprietário foi constituída como resposta a essa demanda. A teoria do proprietário vê a corporação simplesmente como instrumento dos proprietários, em vez de uma entidade com vida própria, separada dos acionistas. Nesse modelo teórico, o proprietário é o centro das atenções. Os ativos pertencem ao proprietário e os passivos são suas obrigações. É atribuída grande importância à determinação do valor do patrimônio líquido e à elaboração do balanço patrimonial que, em última instância, demonstra a riqueza de apenas um ente: o proprietário. Sua expressão fundamental é: Ativo - Passivo = Propriedade (patrimônio líquido).

A entidade empresa como organismo - À medida que o tempo passa, a tendência é de que os sistemas evoluam. Ao final do século XIX, a visão da empresa como sistema mecânico cedia lugar, gradativamente, à visão da empresa como sistema orgânico. Alguns motivos foram preponderantes para que essa transformação ocorresse. Ackoff (1999, p. 3) aponta alguns, a saber: expansão do treinamento e das habilidades da força de trabalho, à medida que a mecanização aumentava; - ampliação das regulamentações, por parte do governo, em relação às condições de trabalho; - participação dos sindicatos nas questões de condições de trabalho, segurança e remuneração. 
Além dos fatores acima apontados, um outro fator de extrema relevância para a transição do entendimento da empresa enquanto máquina para a visão orgânica foi o fato de que muitas empresas não podiam crescer, mesmo que todo lucro fosse reinvestido: era preciso mais capital. Dessa forma, era preciso dividir a propriedade e, conseqüentemente o controle, para se buscar o crescimento. A conseqüência imediata é que, com o capital aberto, a propriedade, em parte, foi diluída (e com ela a força de seus deuses-donos). Os acionistas anônimos, mais distantes da força de trabalho, transformam a propriedade em uma abstração.

Ackoff (1999, p. 4) faz uma interessante analogia quando afirma que, em resposta a essa nova realidade uma instituição e uma profissão foram criadas: a igreja e o clero. Criados exatamente para preencher a lacuna existente, a administração (a igreja) e os executivos (o clero) ${ }^{5}$ foram criados para controlar a empresa, supostamente no interesse dos seus donos, e para se inteirar da vontade dos donos, transmitindo-a a seus funcionários.

As empresas de capital aberto passaram a ser denominadas "corporações", palavra derivada do termo latino "corpus". O presidente assume a cabeça da organização e adjetivos biológicos passaram a ser aplicados às empresas, tais como saudável, madura, doente, vigorosa etc.

As habilidades exigidas dos trabalhadores continuaram a aumentar graças aos contínuos avanços na mecanização. O número de pessoas habilidosas para desempenhar as funções necessárias não era tão grande e o custo de treinamento e substituição de trabalhadores qualificados não era desprezível. Sendo assim, os trabalhadores passaram a ser tratados como peças do corpo - órgãos de difícil reposição - diferenciandose das peças de máquinas facilmente substituíveis. Embora os interesses e objetivos dos funcionários não fossem considerados importantes pelos empregadores, seus desempenhos eram fundamentais.

Segundo Ackoff (1999, p.5), o conceito de empresa como sistema biológico começou a se desgastar durante a Segunda Guerra Mundial, quando mulheres, crianças, jovens e velhos, motivados pelo patriotismo juntaram-se à força de trabalho. Logo, com uma finalidade diferente de, apenas, ter um rendimento a mais.

Um pouco mais adiante no tempo (pós-guerra), a exigência de habilidades e treinamento da força de trabalho aumentou em ritmo acelerado. Cada vez mais, tempo e dinheiro eram investidos em instrução e treinamento de funcionários. Para que houvesse retorno desses investimentos, os funcionários precisavam ser aproveitados de modo mais produtivo e por um tempo maior.

Segundo o relatório Work in América de 1973, apud Ackoff (1999, p. 5), uma parte dos trabalhadores norte-americanos estava insatisfeita com a qualidade de sua vida profissional. Um dos principais problemas é que o trabalho (e suas relações) não mudou com rapidez suficiente para acompanhar as mudanças ocorridas nas atitudes, aspirações e valores por parte dos trabalhadores. Um trabalho interessante passou a ter o mesmo valor que um trabalho apenas bem remunerado.

Não obstante, de tudo o que já foi exposto sobre os motivos da exaustão da empresa como sistema orgânico, o ponto de maior relevância para a transição foi (e está sendo) a pressão de outros grupos de interesse, tanto dentro como fora da organização. Consumidores e não-consumidores, ambientalistas, trabalhadores em exercício e trabalhadores em potencial, governo, concorrentes e a sociedade em geral, começaram a perceber que estavam sendo afetados tanto pelas organizações das quais faziam parte, como por aquelas com as quais, aparentemente, não estavam diretamente relacionados.

Em um sistema concebido como biológico, as partes podem mostrar uma variedade de comportamento maior que aquelas das máquinas, mas não conseguem mudar as funções que executam.

Influenciadas, conscientemente ou não, pelo conceito de totalidade, que afirma que os subsistemas interagem e sempre somos partes integrantes de um sistema mais amplo, tais noções contribuíram para forçar uma transformação no modo de pensar, por

\footnotetext{
${ }^{5}$ Na mesma linha de raciocínio do autor citado, acrescenta-se que os executivos (clero) estavam atarefados com as funções de direção, organização etc. O controle exigia técnica de mensuração cada vez mais sofisticada, fazendo-se necessária a ajuda de um especialista em controle.
} 
parte das pessoas, a respeito das organizações, empresas e instituições assemelhadas.

\section{A Contabilidade para uma empresa concebida como organismo}

A Contabilidade deveria atender, entre outros avanços, principalmente à nova estrutura de capitais. Devido à abstração do conceito de proprietário anteriormente evidenciado, uma nova teoria fazia-se necessária, muito mais para evitar que o conceito do proprietário se diluísse totalmente. Era preciso então, identificar quem são os donos (deuses) e quem são as outras partes envolvidas. Essas "outras partes" não tinham finalidades, apenas funções determinadas por seus donos.

Surge então a Teoria da Entidade, uma adequação à teoria do proprietário. Na teoria da entidade, os lucros e as contas são o registro do negócio; as demonstrações financeiras são os relatórios do negócio. As características são: a empresa é uma entidade separada, com identidade própria; os ativos pertencem à entidade e os passivos são suas obrigações, não do proprietário. A ênfase se consubstancia na demonstração do resultado, pois a entidade existe para propiciar o lucro e os acionistas têm interesse no resultado. Numa versão mais tradicional, os acionistas são vistos como sócios do negócio; numa abordagem moderna, são pessoas externas aos negócios. Sua expressão básica é: ativo = obrigações + patrimônio líquido, ou ativo = passivo.

A entidade empresa como sistema social Segundo Ackoff (1999, p.6), em virtude das pressões internas e externas, os executivos despertaram para a necessidade de levar em consideração os objetivos e interesses:

- das partes do sistema que era administrado;

- dos sistemas maiores que continham esse sistema; e

- do sistema que era administrado.

Torna-se cada vez mais difícil, pelo menos do ponto filosófico-conceitual, compreender a organização como sistema mecânico ou biológico. Em conseqüência, começou-se a pensar as instituições como um sistema social, em que as pessoas, individualmente e coletivamente, são importantes e, por que não dizer, a própria razão (objetivo) do sistema.
Os sistemas sociais, então, são vistos como:

- tendo finalidade própria;

- sendo constituídos de partes com finalidade própria;

- parte de sistemas maiores com finalidade própria; e

- contendo outros sistemas com finalidades próprias.

Todos esses fatores passaram a ser importantes para as empresas atuais. E, como um sistema é um todo que não pode ser dividido em partes independentes, seu desempenho nunca é igual à soma das ações de suas partes, consideradas separadamente: é uma função de suas interações.

Da constatação anterior, surgem diversos trabalhos de pesquisa que convergem para o entendimento que, num sistema complexo, quando cada parte é considerada isoladamente, a busca do melhor desempenho possível das partes não conduz necessariamente para o melhor rendimento do sistema como um todo. Segundo Ackoff (1999, p.6), isso teve implicações extremamente importantes para o gerenciamento de uma empresa.

\section{Conseqüências da empresa vista como um sistema social}

Dentre conseqüências apontadas por Ackoff (1999, p.7), destacam-se algumas, tais como:

A função precípua de um sistema não pode ser realizada por nenhuma de suas partes separadamente. Por exemplo, o motor de um automóvel não é capaz de transportar pessoas. Portanto, o gerenciamento eficaz de um sistema deve concentrar-se nas interações de suas partes, e não nas ações empreendidas por essas partes, separadamente. Em conseqüência, surge o conceito de sinergia, que é um aumento no valor das partes de um sistema, derivado da associação destas ao sistema.

Em geral, um sistema social autocrático diminui a variedade de comportamentos disponíveis para as suas partes; um sistema democrático aumenta essa variedade. Uma empresa concebida como sistema social deve atender às finalidades de suas partes $e$ do sistema a que pertence. Deve aumentar a variedade, tanto dos meios quanto dos fins disponíveis, para suas partes e para os sistemas a que pertencem. 
A predisposição de separar as coisas e tratar as partes separadamente é conseqüência do raciocínio analítico. Muitas vezes análise e raciocínio são tomados equivocadamente como sinônimos. No entanto, a análise é uma forma de pensar, a síntese é outra. Infelizmente, segundo Ackoff (1999, p.8), poucos executivos têm consciência dessa alternativa.

A compreensão de um sistema não pode ser obtida através da análise. Um sistema é um todo cujas propriedades essenciais não são compartilhadas por nenhuma de suas partes isoladamente. Além disso, quando uma parte de um sistema é separada, perde suas propriedades essenciais. Mas, ao se considerar as partes como componentes de um todo - ou seja, sua função nesse todo, será possível captar suas propriedades essenciais e explicar seu comportamento.

De acordo com Ackoff, em pesquisas realizadas nos EUA, calcula-se que pelo menos $90 \%$ dos operários de hoje possam executar seu trabalho melhor que seus chefes. Logo, a função do gerente atual não pode ser supervisioná-los. A função primeira do gerente atual é criar um ambiente em que os subordinados possam se desempenhar tão bem quanto são capazes.

Por conseguinte, o referido autor considera que a principal função financeira do gerenciamento não deveria ser maximizar o retorno do capital investido, mas sim o retorno da mão-de-obra empregada. Uma empresa européia estimou que os empregados usam somente $30 \%$ de sua capacidade em seus trabalhos. Nenhum recurso dentro da empresa é tão subutilizado. Ackoff (1999, p.10) afirma que, enquanto as empresas não aprenderem a utilizar seus funcionários, terão problemas de qualidade. É necessário se desvencilhar das descrições de cargos. Isso impede que as pessoas realizem o seu potencial, pois são baseadas na premissa de que as pessoas que as preparam sabem como executar uma tarefa melhor que as pessoas que devem executá-las. Em geral, essa premissa é falsa.

O desenvolvimento da empresa e das pessoas nela envolvidas deve ser o principal objetivo. Portanto, a segunda responsabilidade fundamental dos executivos é desenvolver aqueles por quem são responsáveis. Os executivos precisam tornar-se educadores. A melhoria da qualidade pode ser obtida mais através da educação que da supervisão.

A terceira tarefa fundamental dos executivos é gerenciar as interações dos funcionários com seus responsáveis, entre as unidades, internamente, e as interações da organização com o ambiente.

\section{A Contabilidade para uma entidade concebida como um sistema social.}

Talvez seja esse o maior desafio da Contabilidade, atualmente: proporcionar uma adequação em sua estrutura conceitual que seja capaz de atender aos anseios sociais.

Nenhuma evolução se dá abruptamente: ela é assim como o alvorecer ou o cair da noite - acontece gradativamente, impossível de ser percebida totalmente no instante em que acontece ${ }^{6}$. Nesse sentido, uma reflexão mais aprofundada desse tópico mereceria um outro trabalho. No entanto, tenta-se de forma concisa identificar traços dessa eminente transição. Muitas escolas do ponto de vista da teoria expressam essa passagem. Identificam-se as principais, como:

A teoria do comando que, na visão de Goldberg apud ludícibus (1994, p. 137), gera o entendimento de que a atenção principal da Contabilidade deveria ser centralizada no controle econômico efetivo dos recursos usados pelos gerentes ou comandantes de uma empresa.

Já na teoria dos fundos, o "fundo", unidade de operação, é o centro de interesse. A entidade é depositária de confiança dos ativos. Este ativo é cada vez mais impessoal em vez de personalizado (ativo sob restrições, delimitações). Em conseqüência, o patrimônio residual representa uma restrição final. Logo, a demonstração do resultado não deve privilegiar o valor final, e sim, possibilitar que os usuários possam deduzir daquela resultados significantes para seus propósitos. Sua expressão fundamental pode ser

\footnotetext{
6 Talvez este parágrafo pareça um tanto subjetivo demais para um texto dito “científico". Aproveitando-se o ensejo, pergunta-se: filosofia, crenças e ciências são subsistemas do pensamento imunes aos efeitos de interdependência?
} 
expressa pela equação: Ativos $=$ Restrições sobre ativos (fundos).

A teoria do agenciamento deriva da teoria do comando, no entanto, a ênfase é dada à informação. Assim, busca-se um modelo para efetuar análise de valor das informações gerenciais. Algumas características se destacam nessa teoria:

Essa escola tenta explicar as relações contratuais entre os agentes e seus interesses pessoais. Sendo assim, procura determinar as formas ótimas que tais contratos devem assumir, para que seja proporcionada a convergência entre os interesses dos indivíduos e os objetivos da entidade.

A informação deve ser tratada como um bem econômico. Através da informação, pretende-se exercer o controle do sistema. Assim, os acionistas imaginam controlar a administração central que, por sua vez, imagina controlar os gerentes, cuja delegação de competências Ihes outorgou responsabilidades de tomadas de decisões na empresa.

Aqui já se observam traços marcantes da "era da informação" e todos os seus correspondentes, tais como a visão da empresa como sistema, a informação como meio capaz de controlar o sistema. No entanto, essa escola ainda representa um esboço "pálido" 7 da cibernética atual.

Para concluir essa contraposição, escolheu-se a teoria do empreendimento como a teoria contábil que mais se aproxima da necessidade de focalizar a empresa como um sistema social. Essa teoria, segundo ludícibus (1994, p. 137), é uma extensão da teoria da entidade, ampliando a abstração da propriedade. Assim, considera que uma entidade contábil é uma instituição social mantida para benefício de muitos grupos interessados, tais como: acionistas, credores, empregados, clientes, governo e o público em geral. De certa forma, essa teoria pode ser considerada como uma teoria social da Contabilidade. Apesar da teoria do empreendimento (empresa) caminhar contrária ao ponto de vista tradicional, que defende que o resultado seja para os "proprietários", pode ser uma teoria cujo tempo é chegado.

\section{4) ENFOQUE SISTÊMICO NA CONTABILIDADE: UMA NOVA PERSPECTIVA}

Antes de analisar a influência do enfoque sistêmico na Contabilidade, faz-se necessário aprofundar um pouco mais a natureza dos dois enfoques. Sendo assim, antes de fazer uma escolha precipitada na forma de condução do pensamento e, por conseqüência, cristalizar a reflexão na forma "analítico x sistêmico", propõese, conforme Riccio ${ }^{8}$, o verdadeiro enfoque sistêmico: o uso, sempre que possível, do conectivo "and" (adição) em substituição ao "or" (exclusão). Assim, sugere-se: "enfoque analítico \& enfoque sistêmico".

De acordo com Rosnay (1997 p. 1), os enfoques analítico e sistêmico são mais complementares que opostos. Infelizmente, raramente enxergam isso com facilidade.

A aproximação analítica busca reduzir um sistema em seus componentes elementares e, em ordem, estudar os detalhes e entender os tipos de interação que existem entre eles. Modificando uma variável de cada vez, tenta deduzir leis gerais que permitirão predizer as propriedades do sistema. Para tornar esta predição possível, devem ser invocadas as leis de aditividade das propriedades elementares. Tal procedimento é valido para os sistemas homogêneos, compostos de elementos semelhantes e interações fracas. Assim, as leis da estatística se aplicam prontamente e permitem entender o comportamento da "complexidade desorganizada".

As leis de aditividade das propriedades elementares não se aplicam a sistemas altamente complexos, compostos de uma diversidade de elementos unidos por interações fortes. Estes sistemas devem ser abordados através de métodos novos. $\mathrm{O}$ propósito do enfoque sistêmico é considerar um sistema em sua totalidade, em sua complexidade e em sua própria dinâmica. Por simulação, a pessoa pode "animar" um sistema e observar em tempo real os efeitos dos tipos diferentes de interações entre seus elementos.

\footnotetext{
${ }^{7}$ No atual estágio dos sistemas contábeis, a palavra controle ainda está muito identificada como uma simples prestação de contas entre pessoas (personificação) e sobretudo carregada de um senso ainda excessivo de vigilância. Espera-se que o sentido do termo controle, nos sistemas contábeis, evolua para o monitoramento, através da informação, dos objetivos dos subsistemas, alinhados com objetivos gerais e mais amplos.

${ }^{8}$ Essa expressão é utilizada pelo professor Riccio nas aulas de Sistemas de Informações na FEA -USP.
} 
A tabela seguinte compara as características das duas abordagens: analítica e sistêmica.

\begin{tabular}{|l|l|}
\hline \multicolumn{1}{|c|}{ Enfoque Analítico } & \multicolumn{1}{c|}{ Enfoque Sistêmico } \\
\hline Isola e se concentra nos elementos & Unifica e se concentra na interação entre os elementos \\
\hline Estuda a natureza das interações & Estuda os efeitos de interações \\
\hline Enfatiza a precisão dos detalhes & Enfatiza a percepção global \\
\hline Modifica uma variável de cada vez & Modifica grupos de variáveis simultaneamente \\
\hline $\begin{array}{l}\text { Valida fatos por meio de prova experimental dentro do corpo } \\
\text { de uma teoria }\end{array}$ & $\begin{array}{l}\text { Valida fatos por comparação do comportamento do modelo } \\
\text { com realidade }\end{array}$ \\
\hline $\begin{array}{l}\text { Usa modelos precisos e detalhados, porém pouco úteis } \\
\text { para explicar realidades complexas (exemplo: modelos } \\
\text { econométricos) }\end{array}$ & $\begin{array}{l}\text { Usa modelos que são insuficientes para serem usados } \\
\text { como bases de conhecimento, mas são úteis em decisão e } \\
\text { ação }\end{array}$ \\
\hline $\begin{array}{l}\text { Apresenta uma aproximação eficiente quando as interações } \\
\text { são lineares e fracas }\end{array}$ & $\begin{array}{l}\text { Apresenta uma aproximação eficiente quando as interações } \\
\text { são não-lineares e fortes }\end{array}$ \\
\hline $\begin{array}{l}\text { Conduziu a educação para a disciplina, a segmentação e } \\
\text { para departamentalização }\end{array}$ & \begin{tabular}{l} 
Conduzirá a educação para a interdisciplinaridade \\
\hline Conduz a ação programada em detalhes
\end{tabular} \\
\hline
\end{tabular}

Adaptado de Rosnay (1997, p. 1)

Essa tabela é uma simplificação da realidade, porém , útil em sua concisão. A apresentação é excessivamente dualista e limitada. Numerosos outros pontos de comparação poderiam e mereceriam ser mencionados. No entanto, a tabela tem a vantagem de contrapor as duas abordagens, que são complementares.

Antes de se tentar uma vinculação mais estreita com a Contabilidade, cabe ainda, antes que se cometa um equívoco mais sério, valer-se, para os propósitos deste trabalho, de algumas conclusões (embora parciais), contidas no pensamento de Churchman.

\section{Teoria geral dos sistemas: algumas reflexões}

Seja lá como for que um problema de sistemas seja resolvido: pelo planejador, pelo cientista, pelo político, pelo antiplanejador ${ }^{9}$ ou por quem quer que seja - a solução está errada - mesmo perigosamente errada. Não pode deixar de haver engano em qualquer enfoque sistêmico.

O significado final do enfoque sistêmico, portanto, consiste na criação de uma teoria do engano, e em uma compreensão mais perfeita dos modos pelos quais o ser humano pode enganar-se a respeito de seu mundo e na interação entre esses diferentes pontos de vista. As pessoas não desejam explorar problemas em profundidade com os seus antagonistas. Acima de tudo, não são capazes de tomar sobre si a carga de acreditar realmente que o antagonista possa ter razão. Isto simplesmente não está na natureza do ser humano.

O que está na natureza dos sistemas é uma contínua percepção e decepção, uma contínua revisão do mundo, do sistema total e de seus componentes. A essência do enfoque sistêmico, portanto, é a confusão tanto quanto o esclarecimento. $\mathrm{O}$ enfoque sistêmico começa quando pela primeira vez alguém vê (ou pelo menos tenta ver) o mundo através dos olhos de outrem. Assim, prossegue ao descobrir que toda concepção do mundo é terrivelmente restrita. Por conseguinte, não existem peritos em enfoque sistêmico.

\section{Cibernética e Contabilidade}

Como foi dito anteriormente, a palavra "Cibernética" vem do grego, designando o saber que permite ao piloto conduzir adequadamente a sua embarcação ${ }^{10}$. Por coincidência, durante uma convenção no Rio de Janeiro, um membro da associação de diretores lojistas, talvez

\footnotetext{
${ }^{9}$ Os diversos tipos de papéis (planejador, cientista etc) são formas que Churchman utilizou em sua obra para contra argumentar as diversas percepções da visão sistêmica.

10 O termo Cibernética é adequado ao conceito de controladoria, seja a embarcação empresa, projeto ou programa de governo etc.
} 
investido de um "espírito" cibernético, fez a seguinte afirmação: a Contabilidade está para a empresa assim como a bússola está para o avião ou navio.

Norbert Wiener, considerado o precursor da cibernética, conforme já se salientou neste estudo, resume a nova ciência: a cibernética tem como objetivo buscar uma unidade fundamental entre os mecanismos de controle, em várias ciências diferentes.

A necessidade de controle é inerente ao homem. A Contabilidade, nos seus primórdios, era utilizada como instrumento isolado e fragmentado de registro da movimentação de bens, de débitos e de créditos. Com o surgimento do comércio em grande escala a necessidade de controle aumentou. A Contabilidade desponta como instrumento de controle capaz de fornecer as informações necessárias para o gerenciamento.

Das atividades empresariais dos pequenos artesãos às empresas virtuais dos dias de hoje, a função da Contabilidade permanece, na essência, a mesma: fornecer as informações (e com elas propiciar controle) para que a entidade atinja seus objetivos.

Todos, em última instância, desejam exercer o controle da riqueza que lhes pertence. A Contabilidade é o instrumento predileto para o controle. No entanto, a posição em que se coloca o controlador, muda a maneira e as técnicas de se controlar. Surge então a aparente dicotomia dos grupos de usuários da Contabilidade, divididos em externos e internos. No fundo, ambos desejosos de, efetivamente, exercer o controle do sistema (ou subsistema ao qual pertence), através da informação.

\section{A mudança de cenário}

A Contabilidade, enquanto ciência do controle patrimonial, está diretamente associada ao grau de desenvolvimento econômico, social e institucional das sociedades. Assim é que a Contabilidade teve seu florescer nas cidades de Veneza, Gênova, Florença, Pisa e outras, onde eram avançadas as atividades mercantis, econômicas e culturais, representando o que de mais moderno havia na época. Essa mesma Contabilidade acompanhou o poderio do império naval na época das grandes navegações, fortaleceu-se na revolução industrial com o advento da máquina a vapor e mostrou seu amadurecimento na mesma proporção do fortalecimento do capitalismo. E hoje, em que mundo vivemos ? Que cenário se vislumbra à nossa frente?

Para iniciar a reflexão a partir desse ponto, extraise um trecho de ludícibus (1994, p. 301): "apesar de as sociedades menos desenvolvidas estarem, mesmo nesse setor, sempre a reboque das mais desenvolvidas, o fato inconteste é que o mundo, num futuro próximo, será o mundo dos computadores, dos robôs, das telecomunicações com imagem, da cópia instantânea à distância e da cibernética em geral. Já o é, em grande parte".

Não é fácil perceber uma revolução quando se está no meio dela, porém, com certeza vive-se hoje uma revolução. A empresa de hoje funciona com uma ampla rede de computadores e sistemas de bancos de dados interagindo. Nesse contexto, uma outra pergunta precisa ser respondida: qual o papel da tecnologia no ambiente das empresas, em particular nos seus sistemas de informação?

\section{Tecnologia}

Hoje se pensa em tecnologia, não em termos de máquinas isoladas, mas em termos de sistemas. Não é apenas a tendência da tecnologia de fazer as coisas maiores e melhores. Trata-se de uma transformação, nas categorias básicas de pensamento, da qual as complexidades da moderna tecnologia são apenas uma e, possivelmente, não a mais importante manifestação.

Constata-se que as coisas mudam numa velocidade espantosa. Estima-se que mais de $80 \%$ dos produtos e serviços que existem hoje não existiam em 1945 . E que cerca de $50 \%$ dos produtos e serviços que se usará em 2010 ainda não existem hoje.

O mundo de hoje, a cada dia que passa, graças ao avanço tecnológico, sobretudo das telecomunicações, está mais interligado, mais próximo, mais acessível. Os satélites interligam milhões de computadores. As informações fluem por todo mundo em segundos. A rede de dados corporativos, como o sistema nervoso de uma pessoa, percorre todas as partes da corporação.

O fato é que, as estruturas organizacionais passaram a ser mais colaborativas, aumentando os inter-relacionamentos intra-empresa bem como desta com o mundo que a cerca. Focalizar a empresa como sistema impede certas análises simplificadoras e introduz certa complexidade nos raciocínios. 
Qual o impacto dessa nova realidade, nos sistemas de informações contábeis? Segundo Bio (1976), "é bastante improvável, embora freqüentemente observada na prática, que uma abordagem atomizada e sem consciência do todo, possa produzir reais resultados na melhoria dos sistemas contábeis..." já ludícibus (1994) afirma que a abordagem sistêmica "parece ser uma base profícua para a Contabilidade...".

\section{5) REDES NEURAIS COMO INSTRUMENTO DE APRENDIZAGEM E CONTROLE}

Esta seção propõe descrever alguns tópicos referentes a redes neurais, tais como: seu surgimento, as propostas iniciais, os diversos motivos que levam inúmeros estudiosos a desenvolvê-las, bem como as propostas para sua implementação. No entanto, o objetivo principal deste tópico é mostrar a vinculação das redes neurais com a teoria geral dos sistemas, em particular com a cibernética. Assim, considera-se a rede neural como uma espécie de método para lidar com sistemas complexos.

\section{Um breve histórico}

De acordo com Yuri \& Yuki (1999), as redes neurais foram desenvolvidas na década de 40, pelo neurofisiologista Warren McCulloch, do Massachusetts Institute of Technology, MIT, e pelo matemático Walter Pitts. Dentro do espírito cibernético, os pesquisadores fizeram uma analogia entre as células nervosas vivas e o processo eletrônico.

De forma simplificada, diz-se que uma rede neural é uma estrutura de processamento de informação, distribuída paralelamente na forma de um grafo direcionado, com algumas restrições e definições próprias. Um grafo direcionado é um objeto geométrico que consiste num conjunto de pontos, chamados nós, ao longo de um conjunto de segmentos de linhas direcionadas entre eles.

Ao contrário dos sistemas heurísticos, assim chamados porque procuram obter sistemas inteligentes baseados em lógica e em processamento simbólico (por exemplo, os sistemas especialistas), as redes neurais artificiais se inspiram em um modelo biológico para a inteligência, isto é, na maneira como o cérebro é organizado em sua arquitetura elementar e como é capaz de executar tarefas computacionais.
A idéia de construir uma máquina que de certa forma tivesse capacidade de "pensar" sempre inquietou os homens de ciência. Minsky (1998, p.1), do MIT, afirma: "o maior desafio é dar bom senso às máquinas".

Para auxiliar a compreensão do assunto, procurase a comparação com o funcionamento de células do cérebro humano, nas quais se baseou todo o funcionamento das unidades componentes das redes neurais. Sem dúvida nenhuma, a aprendizagem pode levar a alterações estruturais no cérebro. A cada nova experiência do indivíduo, redes de neurônios são rearranjadas, outras tantas sinapses são reforçadas e múltiplas possibilidades de respostas ao ambiente tornam-se possíveis.

A plasticidade neural é a propriedade do sistema nervoso que permite o desenvolvimento de alterações estruturais em resposta à experiência, como adaptação a condições mutantes e aos estímulos repetidos. As redes neurais artificiais pretendem adquirir plasticidade ou auto-organização.

\section{Cérebro \& Computador}

O organismo humano é uma fonte de motivação e proporciona diversos indícios para o desenvolvimento de algoritmos de aprendizado e adaptação. Uma diferença que se busca reduzir é que os computadores funcionam de modo seqüencial, proporcionando maior eficiência na resolução de tarefas, nas quais devem ser obedecidas etapas. Já o cérebro humano funciona de modo paralelo, é extremamente conectado e eficiente na resolução de tarefas com muitas variáveis.

Um outro fator de diferenciação é que as máquinas atuais baseiam seu processamento explicitamente em modelos matemáticos. As redes neurais não são baseadas em modelos, embora utilizem cálculos matemáticos para efetuar suas operações. Podem coordenar diversos graus de liberdade durante a execução de tarefas em ambiente desestruturado.

A operação de uma célula da rede assim se resume: sinais são apresentados à entrada; cada sinal é multiplicado por um peso que indica sua influência na saída da unidade. Calcula-se, então, a soma ponderada dos sinais que produz um nível de atividade; se esse nível excede um limite (threshold) a unidade produz uma saída. A função básica de um neurônio é somar as entradas e retornar uma saída, caso esse valor seja maior que o threshold. 
Outra característica diferenciadora das redes neurais é o treinamento. As redes aprendem através de exemplos. A rede neural é capaz de extrair regras básicas a partir de dados reais, diferindo da computação programada, na qual é necessário um conjunto de regras rígidas pré-fixadas e algoritmos. A maioria dos modelos de redes neurais possui alguma regra de treinamento, na qual os pesos de suas conexões são ajustados de acordo com os padrões apresentados.

A rede neural é dividida em camadas que se classificam em três grupos: camada de entrada, em que os padrões são apresentados à rede; camadas intermediárias ou ocultas, em que é feita a maior parte do processamento, por meio das conexões ponderadas (consideradas como extratoras de características); e as camadas de saída, em que o resultado final é apresentado.

\section{Objetivos da pesquisa em redes neurais, classificação e processo de aprendizado}

De acordo com Yuri \& Yuki (1999), um dos objetivos da pesquisa na computação é desenvolver morfologias neurais matemáticas, não necessariamente baseadas na biologia, capazes de realizarem funções diversas. Entretanto, na maior parte dos casos, modelos neurais são compostos de muitos elementos não-lineares, que operam em paralelo e são classificados de acordo com padrões ligados à biologia.

Do ponto de vista estrutural, a arquitetura de redes neurais pode ser classificada como: estática, dinâmica ou fuzzy. Diferenças computacionais surgem também, quando se trata da maneira como são feitas as conexões existentes entres os neurônios: no sentido de ida, no sentido de ida e volta, lateralmente conectadas e topologicamente ordenadas ou híbridas.

O processo de aprendizado de uma rede é feito através de iterações e ajustes aplicados a seus pesos. $\mathrm{O}$ aprendizado ocorre quando a rede neural atinge uma solução generalizada para uma classe de problemas. Denomina-se algoritmo de aprendizado um conjunto de regras bem definidas para a solução de um problema. Existem muitos tipos de algoritmos de aprendizado, específicos para determinados modelos de redes neurais, que diferem entre si principalmente pelo modo como os pesos são modificados.
A rede neural se baseia nos dados, para extrair um modelo geral. A fase de aprendizado deve ser rigorosa, a fim de se evitar modelos espúrios. Todo o conhecimento de uma rede neural está armazenado nas sinapses, ou seja, nos pesos atribuídos às conexões entre os neurônios. O procedimento consiste em separar, de $50 \%$ a $90 \%$ dos dados, para o treinamento da rede neural. A escolha deve ser aleatória, a fim de que a rede "aprenda" as regras e não decore exemplos. O restante dos dados só é apresentado à rede neural na fase de testes, a fim de que ela possa "deduzir" corretamente o interrelacionamento entre os dados.

As redes neurais também podem ser classificadas de acordo com as suas aplicações. Nesse sentido pode-se dividi-las em: 1) reconhecimento de padrões; 2) processamento de imagem e visão; 3) identificação de sistema e controle ; e 4) processamento de sinais. É importante verificar que determinada aplicação de um sistema baseado em rede neural não precisa ser classificada em apenas um dos itens acima. Uma gama muito grande de aplicações de redes neurais artificiais já está presente no nosso dia-adia; alguns exemplos são:

- prognóstico de mercados financeiros;

- reconhecimento de padrões, tais como: reconhecimento ótico de caracteres (OCR); análise de imagens;

análise de voz;

análise de aroma e odor - nariz eletrônico.

- análise de pesquisa de mercado;

- robótica;

- classificação de dados;

- controle de processos industriais;

- aplicações climáticas;

- identificação de fraude de cartão de crédito, como no Banco americano Mellon Bank.

As possibilidades de aplicações também se apresentam viáveis no auxílio à tomada de decisões: pode-se citar o uso das redes neurais no diagnóstico médico. Sem dúvida, ela será também usada na controladoria.

Por que utilizar redes neurais? Esta questão ajuda a esclarecer a vinculação deste tópico com os objetivos gerais deste estudo, como também sua vinculação com a teoria geral dos sistemas (especialmente com a cibernética). Em resposta à pergunta formulada, tem- 
se que os sistemas de computação baseados em redes neurais têm a capacidade de receber, ao mesmo tempo, várias entradas e distribuí-las de maneira organizada. Geralmente, as informações armazenadas por uma rede neural são compartilhadas por todas as suas unidades de processamento. Essa característica contrasta com os atuais esquemas de memória, nos quais a informação fica confinada em um determinado endereço. No processo de armazenagem utilizado pelas redes neurais, a informação parece ter representação redundante, porém, o fato significa que, mesmo quando parte da rede é destruída, a informação ainda estará presente, podendo ser recuperada.

A principal força das redes neurais é sua habilidade de adaptação e aprendizagem, sua capacidade de generalização e, ainda, a habilidade de aproximar qualquer função contínua não-linear com um grau de correção desejado.

\section{6) ALGUMAS REPERCUSSÕES NA CONTABILIDADE E CONTROLADORIA}

Segundo Hendriksen (1999, p.49), passados 500 anos, Pacioli se sentiria muito confortável com os sistemas contábeis encontrados hoje. Certamente, vários instrumentos financeiros o surpreenderiam. No entanto, uma vez que fosse explicado que simplesmente representam novas formas de créditos a serem lançados no lado direito do balanço, terminaria a surpresa. De acordo com o autor citado, de Pacioli aos dias de hoje, o mundo sofreu uma revolução informacional que deveria ter afetado a Contabilidade de maneira dramática. Entretanto, a Contabilidade ainda está por tirar proveito das novas invenções que prometem revolucionar a sociedade.

Uma outra constatação que se faz é que o governo intervém direta e indiretamente na economia, mesmo nos regimes ditos capitalistas. Não obstante, na maioria das sociedades, o principal motor da economia ainda seja a busca do lucro por investidores individuais, o que, via de regra, dá-se através das ações de empresas.

Num regime "não-capitalista" (creio não existir nenhum regime totalmente capitalista, como também nenhum totalmente "não-capitalista"), a relação de propriedade é diferente. Em conseqüência, torna-se difícil definir o que é patrimônio dos proprietários.

Ainda segundo Hendriksen (1999, p.115), a caracterização da economia como privada e capitalista levou o Financial Accounting Standards Board (FASB) a sugerir que o objetivo da informação contábilfinanceira é fornecer informação útil para os que tomam decisões econômicas a respeito de empresas, bem como sobre investimentos ou empréstimos. A confecção de uma lista de todos os possíveis tomadores de decisões econômicas é longa e inclui proprietários, credores, fornecedores, funcionários e administradores. Considera-se que cada um deles fez um investimento na empresa e tem algum interesse no resultado desse investimento: os proprietários esperam receber dividendos, os credores esperam juros, os fornecedores esperam pagamentos, e os funcionários e administradores esperam remunerações em forma de salário e pró-labore. A empresa deve gerar caixa suficiente para proporcionar o retorno desejado aos investimentos efetuados por esses grupos.

Apesar da tentativa de definir investidores da maneira mais ampla possível, o enfoque do FASB, segundo Hendriksen (1999, p. 115), ressalta o papel primordial do proprietário. Por exemplo, na seção sobre administração, o FASB determina que a divulgação financeira deve fornecer informação que seja "útil aos administradores e diretores na tomada de decisão de acordo com os interesses dos proprietários (acionistas) no uso dos recursos a ela entregues".

A premissa de que os usuários têm interesses comuns tem atraído críticas de diversas fontes. Beaver apud Hendriksen (1999, p. 115), defende que os usuários são heterogêneos e não homogêneos. Demandas heterogêneas geram perguntas difíceis e complicadas para as autoridades regulamentadoras.

\section{Interdisciplinaridade}

Outra repercussão que se pretende destacar é a questão da interdisciplinaridade. A Biblioteca Nacional de Medicina estima que o conhecimento médico publicado está dobrando em tamanho a cada quatro anos. Em todos os campos do conhecimento, de certa forma, é impossível a um único cientista abranger qualquer coisa que seja maior que o seu minúsculo campo de especialidade. A conseqüência, segundo Miles apud Sabbatini (1998, p.1), é que:

"à medida que o conhecimento explode e se fragmenta, torna-se impossível para um indivíduo compreender os diversos fragmentos. Para evitar se afogar neste crescente oceano 
de conhecimento, cada um de nós tipicamente se agarra em apenas um ou dois 'objetos flutuantes' como se nossa vida dependesse deles, impedindo-nos assim, de olhar a nossa volta. Tentar enxergar para mais além desses poucos fragmentos, significa ser subjugado pelo tamanho deste oceano. Para evitar isso, preferimos permanecer ignorantes de tudo, menos de nossos próprios domínios."

De acordo com Nissani apud Sabbatini (1998, p.1), uma disciplina é "algo auto-contido e isolado, o qual possui sua própria comunidade de especialistas com componentes distintos tais como metas, conceitos, habilidades e metodologias". Interdisciplinaridade, por outro lado, é "a união dos componentes distintos de duas ou mais disciplinas", conduzindo a novos conhecimentos que não seriam possíveis sem essa integração. A multidisciplinaridade, segundo o autor, ocorre quando as disciplinas trabalham lado a lado em distintos aspectos de um único problema. A interdisciplinaridade ocorre quando as disciplinas se integram e colaboram entre si. O grau de interdisciplinaridade pode variar em muitos domínios. Nissani propõe caracterizar o grau de integração interdisciplinar em quatro critérios: 1) o número de disciplinas; 2) o grau de similaridade entre elas; 3 ) a novidade e criatividade envolvida na combinação, e 4) o grau de integração.

O autor ainda destaca que a interdisciplinaridade também muda e evolui. Aquilo que foi interdisciplinaridade no passado, como a integração entre biologia e física, tornou-se uma disciplina (biofísica). A informática médica é agora um curso universitário em nível de graduação na Alemanha e no Canadá.

Por tudo que foi exposto, acredita-se que o modelo departamental, em que as disciplinas são isoladas, ensinadas e pesquisadas separadamente, com muito pouco em comum, está condenado. Tal procedimento atrapalha a interação e a integração. Os estudantes não aprendem como trabalhar em equipes interdisciplinares, como pensar de maneira interdisciplinar e, deste modo, eles simplesmente passarão a repetir as limitações dos seus próprios professores. O desdobramento da interdisciplinaridade exigirá uma verdadeira revolução, uma reforma abrangente em nossos laboratórios e escolas. A neurociência tem sido exemplar em mostrar os novos caminhos. Em todo o mundo, muitos centros de pesquisa e programas educacionais interdisciplinares e multidisciplinares têm sido fundados com sucesso.

Nesse contexto, vislumbra-se uma abordagem adequada para a Contabilidade. A figura a seguir ${ }^{11}$ esboça esta percepção.

\section{Diversos Enfoques}

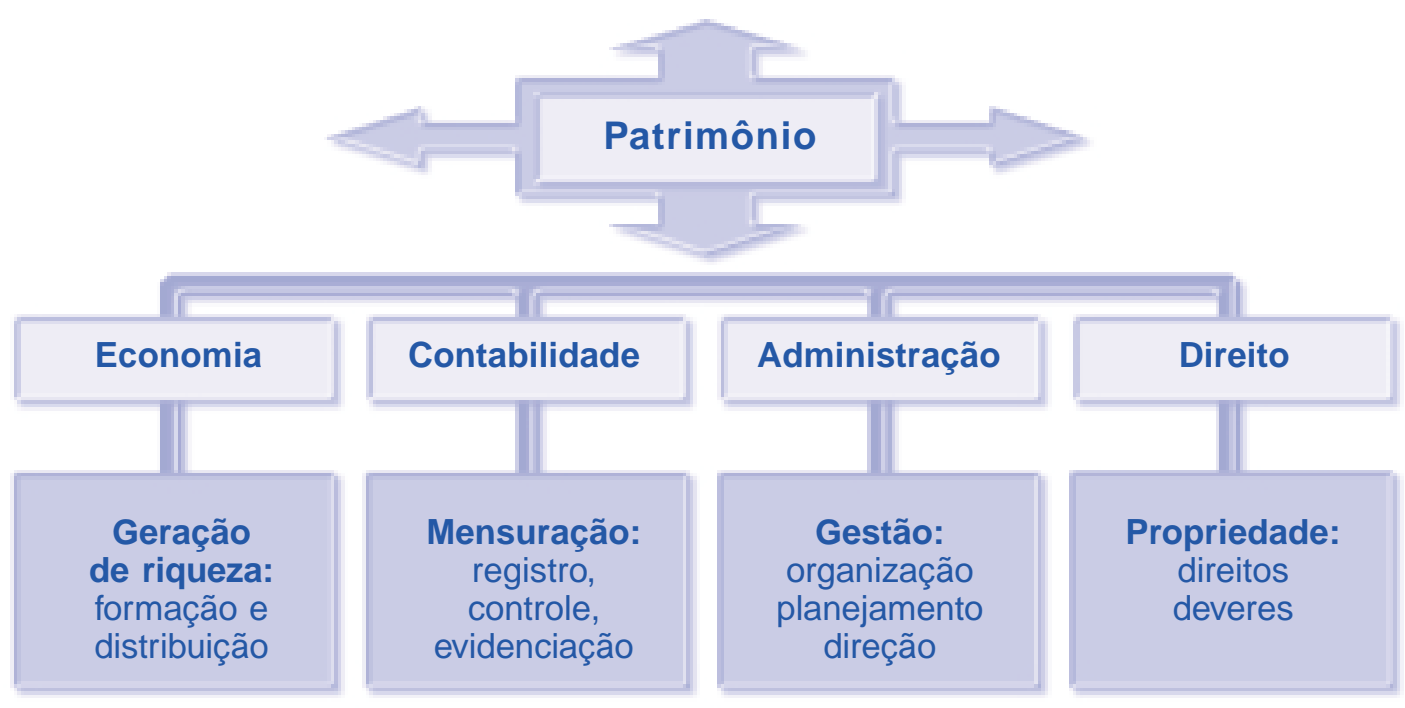

Accountability - Controladoria - Gestão de empresas

${ }^{11}$ Não se pretende, neste trabalho, explorar esta proposição em profundidade, apenas identificá-la como conseqüência do enfoque sistêmico e, em específico, da interdisciplinaridade. 
Com o objetivo de viabilizar programas interdisciplinares, um novo tipo de profissional está sendo necessário: o profissional interdisciplinar. $\mathrm{Na}$ verdade, o que se deseja é alguém que seja capaz de trabalhar facilmente com os especialistas das áreas que estão sendo integradas, interagindo simultaneamente com vários deles. Esse profissional deve ter uma visão abrangente do projeto, identificando como e quando as disciplinas vão interagir.

\section{A Contabilidade e sua importância Social}

A Contabilidade tem por objetivo final o fornecimento de informações úteis para seus usuários. Os modelos de decisão são constituídos a partir da concepção do usuário da informação contábil. Guerreiro (1989, p.38) afirma que os complexos programas do tomador de decisão são regidos pelos seus sistemas genéticos (biológicos) e culturais. Transferindo esta discussão para um aspecto macro, constata-se que o tomador de decisão está inserido em um contexto mais amplo de objetivos, representando o elemento final de um segmento social.

É importante ressaltar que a Contabilidade é resultado direto dos modelos de decisão utilizados pelos usuários da informação contábil. Fatores ambientais agem sobre os usuários e estes direcionam os propósitos dos sistemas contábeis. Todo sistema político-econômico-social interfere na modelagem do processo de decisão do usuário. Para Schmidt (1996), a Contabilidade é resultado desse modelo, independentemente do tipo de informação exigida pelo usuário em particular.

Taylor apud Shmidt (1996, p.419 e 420) tentou demonstrar que a Contabilidade, assim como qualquer ramo de conhecimento social, é um reflexo do meio em que está inserida. O referido autor apresentou as seguintes influências:

1) tipo de economia envolvida: agrícola, industrializada, turismo etc;

2) tipo de sistema legal: baseado em lei ordinária etc;

3) sistema político: democrático, totalitário etc;

4) natureza da propriedade dos negócios: iniciativa privada, socialista, comunista etc;

5) dimensão e complexidade das firmas: conglomerados, negócios individuais etc;
6) clima social: consumismo, laissez faire etc;

7) estabilidade da moeda: moeda estável, instável;

8) sofisticação das práticas de gerenciamento operacional e da comunidade financeira: sofisticadas, não sofisticadas;

9) existência de legislação específica no campo contábil: existência ou não;

10) padrão de crescimento da economia: crescente, estável, declinante; e

11) sistema educacional: desenvolvido ou não etc.

Dentre os fatores que mais influenciaram os sistemas contábeis gerenciais, estão as filosofias de administração: Total Quality Management (TQM); Just-in-Time (JIT); Total Quality Control (TQC); Activity Based Costing (ABC); Gestão Econômica (GECON) etc.

O que se acrescenta, neste estudo, é que, apesar da aludida pressão dos grupos sociais, um significativo segmento da população não entende a informação contábil. A população não interessada na informação contábil não exerce diretamente nenhuma influência no estabelecimento dos objetivos dos sistemas contábeis. Entretanto, indiretamente, todo ambiente do sistema faz algum tipo de pressão sobre a Contabilidade.

Uma reflexão que se pretende fazer é que, se o sistema contábil é fruto do meio (nesse sentido sofre a ação - é paciente), o sistema contábil também influencia o meio (é causador da ação - é agente). Assim, ousar-se-ia dizer que a sociedade também é, de certa forma, um reflexo da sua Contabilidade.

O Sistema Contábil, ao identificar, mensurar, registrar, acumular e evidenciar a variação da riqueza da entidade, ajuda a torná-la eficiente e eficaz, contribuindo assim para o bem estar social. E ainda, ao evidenciar a geração e distribuição dessa riqueza, produzida pelas entidades, ajuda na construção de uma sociedade melhor. Seja do ponto de vista da justiça, da democracia ou da fraternidade.

Alguém poderia contra-argumentar que a Contabilidade, no Brasil, ainda está longe de ser assim considerada. No entanto, dir-se-ia que ela tem todo o potencial para ser instrumento de progresso e bem estar social. O importante é que 
se possa trabalhar numa visão sistêmica, privilegiando a integração. Para isso, é necessária uma aproximação mais efetiva entre universidades, representantes do governo e instituições profissionais. Quem sabe, um trabalho adequado, sobre a demonstração do valor adicionado ${ }^{12}$, que reúna ao mesmo tempo simplicidade, clareza, concisão e principalmente evidenciação do uso e destinação dos recursos escassos da sociedade, possa de alguma forma acelerar esse processo. A informação contábil pode efetivamente contribuir para a percepção e compreensão das entidades empresarias como entes - eminentemente sociais.

\section{REFERÊNCIAS BIBLIOGRÁFICAS}

ACKLEY, D.H., Hinton, G.E., and SEJnowski, T.J. $A$ learning algorithm for Boltzmann machines. Cognitive Science, 1985.

ACKOFF, Russel. Conferência planejamento estratégico 26/03/99. MBA executive internacional.

ALEKSANDER, I., Thomas, W.V., and Bowden, P.A.. WISARD, a radical step forward in image recognition. Sensor Review, 1984.

BEER, Stafford. Cibernética e Administração Industrial. Rio de Janeiro: Zahar, 1969.

BEER, Stafford. The heart of enterprise. Chichester, New York, Brisbane, Toronto: John Wiley \& Sons, 1979.

BENNATON, Jocelyn Freitas. O que é cibernética. São Paulo: Brasiliense, 1984.

BERTALANFFY, Von Ludwig. Teoria geral dos sistemas. Petrópolis: Vozes, 1972.

BERTALANFFY, Von Ludwig. General system theory. Foundations, development e applications. New York: George Braziller, 1968.

BUCKLEY, Walter Frederick. A sociologia e a moderna teoria dos sistemas. Tradução de Octavio Mendes Cajado. São Paulo: Cultrix/ Edusp, 1971.

$\mathrm{BIO}$, Sérgio Rodrigues. Contribuições à formulação de um plano de longo prazo para o desenvolvimento de um sistema contábil integrado. Dissertação (Mestrado). São Paulo, 1976. FEA-USP.

BRUNO, Edgard Conachione. Das bases de sustentação da contabilidade e da informática. Dissertação (Mestrado). São Paulo, 1994. FEA-USP.

CHURCHMAN, C. West. Introdução à teoria dos sistemas. 2 ed. Rio de Janeiro: Vozes, 1972.

CHURCHMAN, C. West. Introduction to operations research. London, Sydney: John Wiley \& Sons Ltda. 1957.

GUERREIRO, Reinaldo. Modelo conceitual de sistema de informação de gestão econômica: uma conctribuição à teoria da comunicação da contabilidade. São Paulo, 1989 Tese (Doutorado) - FEA-USP.

HENDRIKSEN, Eldon S. and VAN BREDA, Michael F. Accounting theory. Tradução de Sanvincente. São Paulo: Atlas, 1999.

HEYLIGHEN, F. Principia cybernetica rede - (C) URL http://pespmc1.vub.ac.be/ANALSYST.html, 1993.

HOPFIELD, J.J. Neural networks and physical systems with emergent collective computational abilities. Proc. Natl. Acad. Sci. USA, 1982.

IUDícIBUS, Sérgio de. Teoria da Contabilidade. São Paulo: Atlas, 1994.

MATTESSICH, Richard. Methodological preconditions and problems of a general theory of accounting. Accounting Review, julho de 1972.

MINSKY, Marvin. A mente, inteligência artificial e emoções. Revista Cérebro \& Mente № 7 - setembro/ novembro, 1998.

\footnotetext{
12 A título de exemplo de pesquisa na área de Demonstração do Valor Adicionado, cita-se o excelente trabalho do Prof. Dr. Ariovaldo dos Santos para obtenção do título de livre-docente pela FEA/USP, intitulado: Demonstração Contábil do Valor Adicionado - DVA: Um Instrumento Para Medição da Geração e Distribuição de Riqueza das Empresas.
} 
RICCIO, Edson Luiz. Uma contribuição ao estudo da contabilidade como sistema de informação. Tese (Doutorado). São Paulo, 1989. FEA-USP.

ROSNAY, J. Principia cybernetica rede - URL http:// pespmc1.vub.ac.be/ANALSYST.html, 1979.

SABBATINI, Renato M. E. \& CARDOSO, Sílvia H. Interdisciplinaridade e o estudo da mente. Revista Cérebro \& Mente no 6 - junho/agosto, 1998.
SCHMIDT, Paulo. Uma contribuição ao estudo da história do pensamento contábil. Tese (Doutorado). São Paulo, 1996. FEA-USP.

YURI, C. Tatibana \& YUKI, D. Kaetsu. Redes Neurais (c) URL http://www.din.uem.br/ia/neurais.

WIENER, Norbert. Cibernética e Sociedade. O uso humano de seres humanos. Tradução de José Paulo Paes. 2ª ed. São Paulo: Cultrix, 1968. 